\title{
High-dose thiotepa-related neurotoxicity and the role of tramadol in children
}

\author{
Christophe Maritaz $^{1 *}$, Francois Lemare ${ }^{1,4,5}$, Agnes Laplanche ${ }^{2}$, Sylvie Demirdjian ${ }^{1}$, Dominique Valteau-Couanet ${ }^{3}$ \\ and Christelle Dufour ${ }^{3}$
}

\begin{abstract}
Background: Serious neurological adverse events (NAE) have occurred during treatment with high-dose thiotepa regimens of children with high-risk solid tumours. The objective was to assess the incidence of NAE related to high-dose thiotepa and to identify potential contributing factors that could exacerbate the occurrence of this neurotoxicity.

Methods: From May 1987 to March 2011, children with solid tumours treated with high-dose thiotepa were retrospectively identified. Each NAE detected led to an independent case analysis. Potential contributing factors were pre-specified and univariate/multivariable analyses were performed.

Results: Three hundred seven courses of thiotepa (251 patients) were identified. The total dose per treatment ranged from 600 to $900 \mathrm{mg} / \mathrm{m}^{2} .81$ NAE (26\%) were identified. 46 NAE were related to high-dose thiotepa during the first course (18.3\%) and 11 during the second course (19.6\%). The symptoms appeared in a median time of 2 days after the introduction of thiotepa. Central and peripheral symptoms were headaches, tremors, confusion, seizures, cerebellar syndrome, and coma. High-dose thiotepa was reintroduced in 18 cases and symptoms reappeared in 5 children. For 3 patients who had seizures during the first course, premedication with clonazepam for the second course has prevented recurrence of NAE. As contributing factors, brain tumour and tramadol treatment increased the risk of thiotepa-related neurotoxicity by 2 to 6 times respectively.
\end{abstract}

Conclusions: The incidence of neurotoxicity was 18.3\%. Brain tumours and tramadol treatment are risk factors to consider when using high-dose thiotepa. The outcome of patients was favourable without sequelae in all cases and rechallenge with thiotepa was possible.

Keywords: Thiotepa, Neurotoxicity, Tramadol, Pediatrics

\section{What is already known about this subject}

- Little is known about the possible relationship between exposure to high-dose thiotepa and the occurrence of neurological disorders.

- High-dose thiotepa administered below the Maximum Tolerated Dose has never been studied in terms of neurological outcomes.

\section{What this study adds}

- This study estimates the incidence of thiotepa-related neurological complications, unlike the neurotoxicity described when the drug was used beyond the defined limiting dose or combined with another cytotoxic drug or irradiation.

- Our findings show that brain tumour and tramadol treatment could be independently associated with thiotepa-related neurotoxicity.

\section{Background}

1Department of Clinical Pharmacy, Gustave-Roussy cancer campus, 114 Rue

Edouard Vaillant, 94805 Villejuif, France

Full list of author information is available at the end of the article
High-dose chemotherapy (HDCT) with autologous stem cell transplantation (ASCT) has improved the survival of 
children with high-risk solid tumours. The rationale for HDCT is that escalated doses of HDCT may increase survival by capturing putative remnant malignant cells [1]. The rationale for ASCT following HDCT is a planned rescue for HDCT-related severe haematological toxicity [2].

The HDCT regimens are generally based on the use of alkylating agents [3]. Among them, thiotepa $\left(\mathrm{N}, \mathrm{N}^{\prime}, \mathrm{N}\right.$ "-triethylenethiophosphoramide), an organophosphorus compound with the formula $\mathrm{SP}\left(\mathrm{NC}_{2} \mathrm{H}_{4}\right)_{3}$, is one of the few drugs to have demonstrated clear activity at high doses in childhood tumours [4-9]. Thiotepa is extensively metabolized by cytochrome P450. Its major metabolite tepa, has similar alkylating activity [10, 11]. This hepatic biotransformation is mediated by CYP3A4 and CYP2B6, and conjugation is catalyzed by glutathione Stransferase (GST) [12,13]. Following intravenous administration, drug exposure in cerebrospinal fluid (CSF) is almost equivalent to that of the product in plasma [14]. Thiotepa has been reported to possess an elimination half-life of 1.3-5.2 $\mathrm{h}$ and tepa an elimination half-life of 3-21 h [15]. Thiotepa and its metabolites are totally excreted in urine $[15,16]$. Due to its metabolic profile, concomitant administration of thiotepa with CYP3A4 or CYP2B6 inhibitors may increase plasma thiotepa concentrations and potentially decrease the concentrations of the active metabolite tepa. Conversely, concomitant administration of thiotepa with CYP3A4 or CYP2B6 inducers may reduce plasma thiotepa concentrations and increase those of tepa. In addition, there is interindividual variability in product excretion since CYP3A4, CYP2B6, and GST share a genetic polymorphism with some variants which exert a significant impact on the clearance of thiotepa and tepa [17]. Relationships between the pharmacokinetics of the drug and its toxicity have been described [18-21]. Toxicity to the gastrointestinal and central nervous system is dose-limiting and the maximum tolerated dose (MTD) of thiotepa is between 1005 and $1125 \mathrm{mg} / \mathrm{m}^{2}[7,21,22]$.

Little is known about the possible relationship between exposure to high-dose thiotepa and the occurrence of neurological disorders. To our knowledge, high-dose thiotepa administered below the MTD has never been studied in terms of neurological outcomes. One reason for the lack of knowledge is that thiotepa is rarely used alone. In our experience, serious neurological adverse events (NAE) have occurred during treatment with highdose thiotepa regimens. Some of these NAE could lead to life-threatening complications. The objective of the present study was to assess the incidence of NAE related to high-dose thiotepa with ASCT in children with solid tumours and to identify potential contributing factors that could increase the occurrence of this neurotoxicity.

\section{Methods}

\section{Patients}

The institutional review board of the Gustave Roussy Cancer Campus approved this study. The parents/guardians gave their written informed consent for the retrospective analysis of clinical data according to the institutional review board of the Gustave Roussy Cancer Campus. From the institutional pediatric transplantation register, we established a retrospective cohort of all patients treated for a solid tumour with high-dose thiotepa followed by ASCT between May 1987 and March 2011 at Gustave-Roussy, center with expertise in the treatment of complex malignancies. Our analysis focused on neurotoxicity exclusively due to thiotepa, therefore patients treated with thiotepa combined with another cytotoxic drug or radiotherapy were excluded.

\section{Procedures}

All medical and nursing records were reviewed. Demographics data (sex, age, weight, height), race aimed at assessing the influence of the type of metabolism (slow, medium, fast), clinical data (medical and neurological history, allergies, cancer type and site of the primary tumour), and drug exposure (thiotepa and drugs administered concomitantly) from admission to hospital until the day of ASCT were collected for each patient. To assess the impact of potential organic disturbances, biological monitoring of renal and hepatic function from admission to hospital until the day of ASCT was taken into account. Biological monitoring of renal function took into account blood urea and creatinine. The glomerular filtration rate (GFR) was estimated using the Schwartz formula [23]. Monitoring of liver function took into account transaminases (SGOT, SGPT), gamma-GT, bilirubin, and serum protein. Any neurological symptom occurring during the administration of thiotepa or within seven days (5 half-lives) following the end of the last administration of thiotepa was defined as a NAE. Further examinations distinguished symptoms related to progressive disease or to other causes from NAE. NAE were classified according to the National Cancer Institute Common Terminology Criteria for Adverse Events (version 4.03). Each event detected led to a case analysis to assess the neurological outcome.

Causality assessment of adverse drug reactions (imputability) was performed using the algorithm devised by Begaud et al. which is based on a three-stage process: assessment of chronological criteria, clinical and biological findings and symptom evaluation [24]. The method separates intrinsic imputability (possible cause between drug and clinical event) from extrinsic imputability (bibliographical data) using seven criteria divided in two groups: chronology and semiology (symptoms or signs). 
Potential contributing factors were pre-specified and were: (1) sex; (2) age; (3) race; (4) primary tumour site; (5) history of neurological disorders; (6) metabolic disruption; and (7) use of concomitant therapy (antiemetic, antipsychotic, analgesic, antifungals, Proton Pump Inhibitor, and histamine H2-receptor antagonist). Concomitant drugs were determined according to their potential ability to interact with thiotepa metabolism. They were captured the week before, during, and the week after thiotepa exposure.

\section{Statistical analysis}

Some patients had received more than one course of high-dose thiotepa. We decided to retain only one course per patient in order to avoid skewing the statistical analysis by including patients with individual susceptibility. In principle, the first course of high-dose chemotherapy was taken into account in the analysis. The second courses were analyzed separately to study the effect of rechallenge with thiotepa when NAE occurred during the first course. The results are expressed as percentages (qualitative data), or medians and the interquartile range (quantitative data). Concerning the analysis of factors associated with the occurrence of NAE, univariate and multivariable analyses were performed using logistic regression. Variables with a $P$ value below 0.05 in the univariate analysis were selected for the multivariable analysis. The results are expressed as the Odds Ratio (OR) of NAE for each factor; an OR equal to 1 is associated with the reference category of each factor. All statistical analyses were two-sided, with $P$ values of 0.05 or less deemed statistically significant. The software used was SAS, version 9.1.

\section{Results}

Between May 1987 and March 2011, 307 courses of high-dose thiotepa with ASCT were administered to 251 patients (56 patients received 2 courses of high-dose thiotepa). Baseline characteristics of these 251 children are shown in Table 1. The median age of children was 8 years (IQR 5-15) with a sex ratio of 1.4 boys per 1 girl, and the population was predominantly Caucasian (74\%). The total dose of thiotepa per course was $900 \mathrm{mg} / \mathrm{m}^{2}$ for 46 patients (18\%), $720 \mathrm{mg} / \mathrm{m}^{2}$ for 76 patients $(30 \%)$, and $600 \mathrm{mg} / \mathrm{m}^{2}$ for 129 patients (51\%). One hundred and sixteen patients $(46 \%)$ had a primary brain tumour. Twenty children (8\%) had a neurological disorder due to disease when they were admitted to hospital: moderate cerebellar syndrome $(n=9)$, central neuropathy $(n=1)$, peripheral neuropathy $(n=3)$, hemiparesis $(n=3)$, and facial paralysis $(n=4)$. Thirty children exhibited early-stage renal failure upon admission to hospital with a median GFR of $80.5 \mathrm{~mL} / \mathrm{min}$ (IQR, 71-85 $\mathrm{mL} / \mathrm{min}$ ) and a median blood urea level of $4.65 \mathrm{mmol} / \mathrm{L}$ (IQR, 3-6.3 mmol/L).
The 221 patients without renal insufficiency upon admission to hospital had a median GFR of $123.5 \mathrm{~mL} /$ $\min$ (IQR, 111-146 $\mathrm{mL} / \mathrm{min}$ ) and a median blood urea level of $3.9 \mathrm{mmol} / \mathrm{L}$ (IQR, 2.4-4.6 mL/min). On the day of ASCT, early-stage renal failure had persisted with a median GFR of $79 \mathrm{~mL} / \mathrm{min}$ (IQR, 68$82 \mathrm{~mL} / \mathrm{min}$ ) and a median blood urea level of $2.6 \mathrm{mmol} / \mathrm{L}$ (IQR, $1.7-4.5 \mathrm{~mL} / \mathrm{min}$ ) in 12 of these 30 children. No patients had liver disruption at upon admission to hospital (SGPT median $=26 \mathrm{IU} / \mathrm{L}, \mathrm{IQR}$ 18-38; SGOT median $=28$ IU/L, IQR 22-36; total bilirubin median $=8 \mu \mathrm{mol} / \mathrm{L}$, IQR 6-10; GGT median $=16 \mathrm{IU} / \mathrm{L}$, IQR 12-24). Thirteen patients had reversible hepatic cytolysis at the end of the thiotepa regimen without cholestasis (SGPT median $=217 \mathrm{IU} / \mathrm{L}$, IQR 177-253; SGOT median $=156$ IU/L, IQR $143-$ 179; total bilirubin median $=12 \mu \mathrm{mol} / \mathrm{L}$, IQR 10-14; GGT median $=17 \mathrm{IU} / \mathrm{L}, \mathrm{IQR} 8-25$; serum protein median $=59 \mathrm{~g} / \mathrm{L}, \quad$ IQR 53-74). During treatment with thiotepa, 92 patients had required analgesics (42\%). According to the World Health Organization analgesic ladder, 76 patients (35\%) had received simple analgesics such as acetaminophen or nefopam for mild pain, 53 patients (24\%) had received weak opioids such as tramadol, codeine, or dextropropoxyphen for mild to moderate pain, and 9 patients (4\%) had received strong opioids such as morphine or pethidine for moderate to severe pain. Sometimes, patients had received a combination of different analgesics. Regarding anti-emetic support, every child had received at least a 5-HT3 antagonist. The anti-emetic treatment added was alizapride (43\%), or aprepitant (3\%). None of the patients had declared an allergy to analgesics or antiemetic drugs upon admission to hospital.

After reviewing medical and nursing records, 81 NAE (26.4\%) were unveiled during the 307 courses, 69 NAE had occurred during the 251 first courses (27.5\%), and 12 NAE during the $56 \mathrm{~s}$ courses (21.4\%). After assessment of intrinsic and extrinsic imputability, NAE were considered "very likely" related to thiotepa for 13 patients $(16.0 \%)$, "likely" related to thiotepa for 35 patients (43.2\%) and "possibly" related to thiotepa for 9 patients (11.1\%). Twenty-four NAE (29.6\%) were assessed as "dubious" or "unlikely" to be related to thiotepa, and were therefore excluded (Fig. 1). Thus, among the 307 courses of high-dose thiotepa, 57 NAE had occurred (18.6\%). Forty-six NAE had occurred during the 251 first courses (18.3\%), and 11 during the $56 \mathrm{~s}$ courses (19.6\%). In this study, the incidence of high-dose thiotepa-related neurotoxicity was therefore estimated at $18.3 \%$. Five children had experienced NAE during the two courses of high-dose thiotepa. Twenty-eight NAE (24\%) had occurred in patients with a brain tumour and 18 $(13 \%)$ in patients with another primary tumour site. 
Table 1 Patient characteristics

\begin{tabular}{|c|c|}
\hline & Patients $(N=251)$ \\
\hline \multicolumn{2}{|l|}{ Gender } \\
\hline Boys & $145(58 \%)$ \\
\hline Girls & $106(43 \%)$ \\
\hline Age (years; median [IQR]) & $8[5-15]$ \\
\hline \multicolumn{2}{|l|}{ Race } \\
\hline Caucasian & $186(74 \%)$ \\
\hline African & $40(16 \%)$ \\
\hline Others & $25(10 \%)$ \\
\hline Brain tumour & $116(46 \%)$ \\
\hline Medulloblastoma & $71(28 \%)$ \\
\hline $\mathrm{PNET}^{\mathrm{a}}$ & $26(10 \%)$ \\
\hline Pinealoblastoma & $13(5 \%)$ \\
\hline $\mathrm{ATRT}^{\mathrm{b}}$ & $5(2 \%)$ \\
\hline Malignant $\mathrm{GCT}^{\mathrm{C}}$ & $1(0.4 \%)$ \\
\hline Other tumour site & $135(54 \%)$ \\
\hline Osteosarcoma & $50(20 \%)$ \\
\hline Neuroblastoma & $26(10 \%)$ \\
\hline Ewing tumor & $23(9 \%)$ \\
\hline Rhabdomyosarcoma & $20(8 \%)$ \\
\hline Other sarcoma & $4(2 \%)$ \\
\hline Nephroblastoma & $4(2 \%)$ \\
\hline Burkitt lymphoma & $4(2 \%)$ \\
\hline Hepatoblastoma & $2(1 \%)$ \\
\hline Desmoplastic tumour & $2(1 \%)$ \\
\hline Neurological disorder at baseline ${ }^{d}$ & $20(8 \%)$ \\
\hline History of seizure & $13(5 \%)$ \\
\hline \multicolumn{2}{|l|}{ Thiotepa dose } \\
\hline $600 \mathrm{mg} / \mathrm{m}^{2}$ & $129(51 \%)$ \\
\hline $720 \mathrm{mg} / \mathrm{m}^{2}$ & $76(30 \%)$ \\
\hline $900 \mathrm{mg} / \mathrm{m}^{2}$ & $46(18 \%)$ \\
\hline \multicolumn{2}{|l|}{ Concomitant drugs ${ }^{\mathrm{e}}$} \\
\hline Alizapride & $94(43 \%)$ \\
\hline Antibiotic & $49(22 \%)$ \\
\hline Antidepressant & $7(3 \%)$ \\
\hline Antipsychotic & $40(18 \%)$ \\
\hline Aprepitant & $7(3 \%)$ \\
\hline Benzodiazepine & $43(20 \%)$ \\
\hline Histamine $\mathrm{H} 2$-receptor antagonist & $5(2 \%)$ \\
\hline Proton Pump Inhibitor & $7(3 \%)$ \\
\hline Analgesics & $92(42 \%)$ \\
\hline Simple analgesics & $76(35 \%)$ \\
\hline \multicolumn{2}{|l|}{ i.e. acetaminophen, nefopam } \\
\hline Weak opioids & $53(24 \%)$ \\
\hline
\end{tabular}

Table 1 Patient characteristics (Continued)

\begin{tabular}{ll}
\hline & Patients $(N=251)$ \\
\hline i.e. tramadol, codeine, dextropropoxyphen & \\
Strong opioids & $9(4 \%)$ \\
i.e. morphine, pethidine & \\
\hline Data are numbers (\%), unless otherwise stated & \\
aPrimitive NeuroEctodermal Tumour \\
bAtypical Teratoid Rhabdoid Tumour \\
cMalignant Germ Cell Tumour \\
dData missing for one patient \\
eData missing for 31 patients
\end{tabular}

None of the 13 patients with hepatic cytolysis had developed NAE.

The median time to the onset of neurological symptoms was 2 days (range $0-4$ ) after the beginning of the course of thiotepa. Table 2 shows the symptoms described for the $46 \mathrm{NAE}$ identified during the first courses of high-dose thiotepa. Some patients had experienced several symptoms. Most of the NAE symptoms were graded 1 or 2 , corresponding to a mild or moderate disorder. Headache, dizziness, and confusion, graded 1 or 2 , which had occurred in 45 cases (94\%), are the neurological symptoms described in the Summary of Product Characteristics of thiotepa. Six events were graded 3: three cases of headache, dizziness, confusion; one case of tremor; one of seizure; and one of cerebellar syndrome. One case of seizure was graded 4 and resulted in life-threatening consequences. All of these events had disappeared without sequelae in a median interval of 3 days (range 1-8 days). Eighteen patients had been rechallenged with thiotepa, and NAE had reappeared in 5 cases. In 3 patients who had experienced seizure during the first course of thiotepa, prophylactic treatment with clonazepam had been administered and no further NAE had occurred. Fig. 1 presents a summary of all NAE-related data observed.

Table 3 shows details of the univariate analysis performed on the $46 \mathrm{NAE}$ which had occurred during the first courses. A brain tumour (OR, 2.1; 95\% CI, 1.1 to 4.0; $P=0.03$ ), a neurological disorder at baseline (OR, 3.4; $95 \% \mathrm{CI}, 1.3$ to $8.8 ; P=0.02$ ), alizapride (OR, $2.0 ; 95 \%$ $\mathrm{CI}, 1.0$ to $4.0 ; P=0.04)$, and weak opioids (OR, $6.1 ; 95 \%$ CI, 3.0 to $12.4 ; P<0.0001$ ) were identified as risk factors for thiotepa-related NAE. The weak opioids used were tramadol $(n=46)$, codeine $(n=5)$, and dextropropoxyphen $(n=2)$. NAE had occurred in 21 cases when tramadol had been used (46\%; $P<0.0001$ ), in two cases with codeine $(40 \% ; P=0.26)$, and in one case with dextropropoxyphen $(50 \% ; P=0.29)$. The risk of NAE was not significantly associated with gender $(P=0.41)$, age $(P=0.48)$, race $(P=0.51)$, a history of seizure $(P=0.27)$, renal failure $(P=0.98)$, or other concomitant drugs. Although not significantly associated with the dose of thiotepa $(P=$ 0.18 ), we observed a trend towards an increasing 


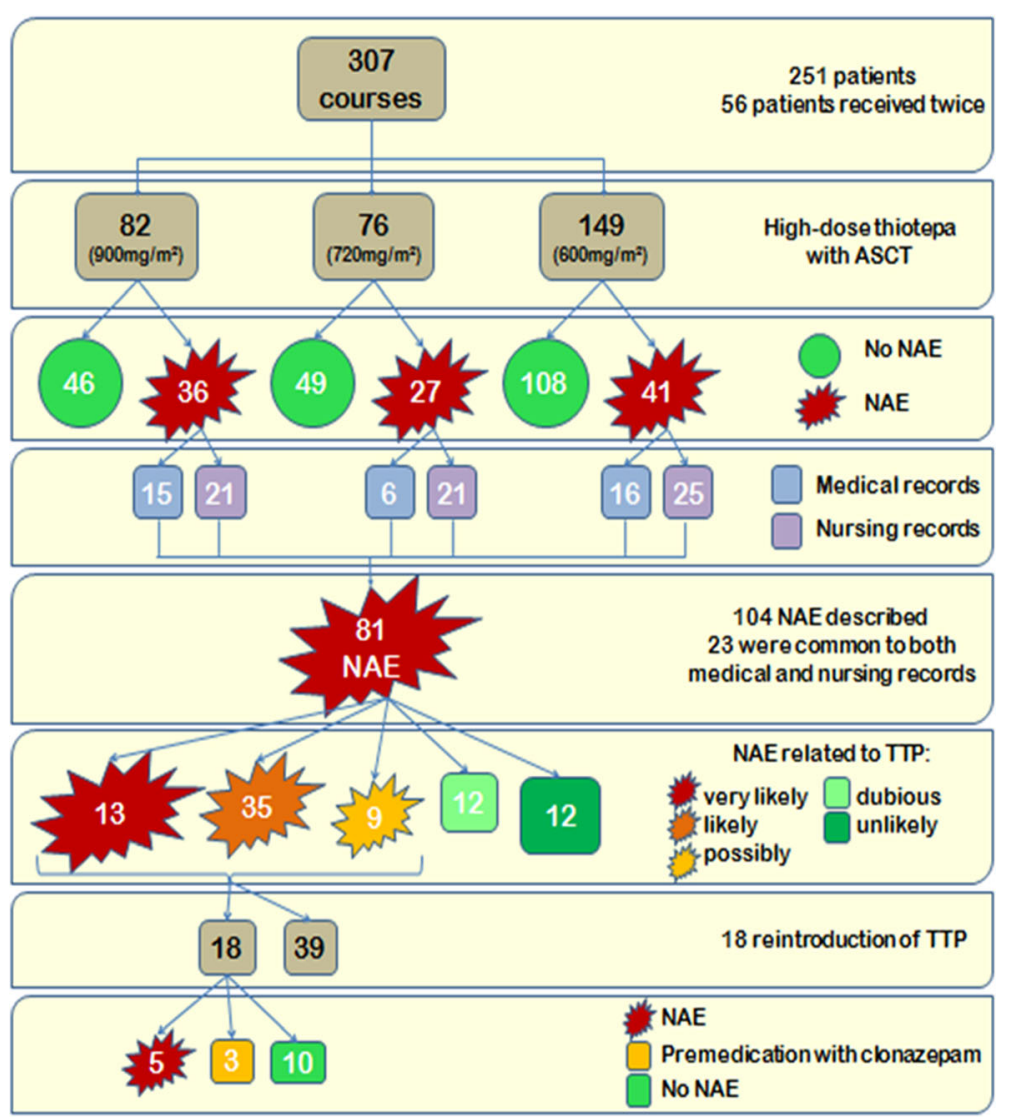

Fig. 1 Summary chart of neurological adverse events (NAE)

dose-dependent rate of neurotoxicity $\left(600 \mathrm{mg} / \mathrm{m}^{2}\right.$ : 14\%; $720 \mathrm{mg} / \mathrm{m}^{2}: 22 \% ; 900 \mathrm{mg} / \mathrm{m}^{2}: 24 \%$ ).

In the multivariable analysis, a brain tumour and a weak opioid (tramadol) were identified as independent risk factors for thiotepa-related NAE (Table 3). Patients with a brain tumour were found to have a greater risk of developing NAE than patients with another primary tumour (OR, 2.2; 95\% CI, 1.0 to $4.6 ; P=0.04)$. The use of tramadol for analgesia was confirmed as a highly significant contributing factor for NAE (OR, 6.3; 95\% CI, 3.0 to $13.4 ; P<0.0001)$.

\section{Discussion}

In this imputability analysis, the incidence of neurotoxicity due to high-dose thiotepa was estimated at $18.3 \%$. To our knowledge, this is the first study to describe the

Table 2 Description of neurological adverse events (NAE)

\begin{tabular}{|c|c|c|c|c|c|c|}
\hline \multirow{3}{*}{ Symptoms } & \multicolumn{6}{|c|}{ Patients $(N=251)$} \\
\hline & \multirow[t]{2}{*}{$n$} & \multicolumn{5}{|c|}{$\mathrm{NCl}$ CTCAE grade } \\
\hline & & 1 & 2 & 3 & 4 & 5 \\
\hline Headache, dizziness, confusion & $48(15.6 \%)$ & $23(47.9 \%)$ & $22(45.8 \%)$ & $3(6.3 \%)$ & & \\
\hline Blurred vision & $3(1.0 \%)$ & $3(100 \%)$ & & & & \\
\hline Tremor & $8(2.6 \%)$ & $3(37.5 \%)$ & $4(50 \%)$ & $1(12.5 \%)$ & & \\
\hline Neuralgia & $2(0.7 \%)$ & $1(50 \%)$ & $1(50 \%)$ & & & \\
\hline Seizure & $6(2.0 \%)$ & $2(33.3 \%)$ & $2(33.3 \%)$ & $1(16.7 \%)$ & $1(16.7 \%)$ & \\
\hline Pyramidal tract syndrome & $1(0.3 \%)$ & & $1(100 \%)$ & & & \\
\hline Cerebellar syndrome & $3(1.0 \%)$ & & $2(66.7 \%)$ & $1(33.3 \%)$ & & \\
\hline Opsoclonus-myoclonus syndrome & $1(0.3 \%)$ & & $1(100 \%)$ & & & \\
\hline Coma & 1 (0.3\%) & & 1 (100\%) & & & \\
\hline
\end{tabular}


Table 3 Univariate and multivariate logistic regression analysis of factors contributing to NAE

\begin{tabular}{|c|c|c|c|c|c|c|}
\hline & $n$ & NAE (\%) & univariate $P^{a}$ & $\begin{array}{l}\text { univariate } \\
\text { OR }(95 \% \mathrm{Cl})\end{array}$ & multivariate $P^{b}$ & $\begin{array}{l}\text { multivariate } \\
\text { OR }(95 \% \text { Cl) }\end{array}$ \\
\hline \multicolumn{7}{|l|}{ Gender } \\
\hline Boys & 145 & $24(17 \%)$ & & & & \\
\hline Girls & 106 & $22(21 \%)$ & 0.41 & $1.3(0.7-2.5)$ & & \\
\hline \multicolumn{7}{|l|}{ Age } \\
\hline No NAE & 205 & $9.3(6.3)^{f}$ & & & & \\
\hline Yes NAE & 46 & $8.6(5.2)^{f}$ & $0.48^{c}$ & & & \\
\hline \multicolumn{7}{|l|}{ Race } \\
\hline Caucasian & 186 & $31(17 \%)$ & & & & \\
\hline African & 40 & $9(23 \%)$ & $0.51^{e}$ & & & \\
\hline Others & 25 & $6(24 \%)$ & & & & \\
\hline \multicolumn{7}{|l|}{ Brain tumour } \\
\hline No & 135 & $18(13 \%)$ & & 1 & & 1 \\
\hline Yes & 116 & $28(24 \%)$ & 0.03 & $2.1(1.1-4.0)$ & 0.04 & $2.2(1.0-4.6)$ \\
\hline \multicolumn{7}{|c|}{ Neurological disorder at baseline } \\
\hline No & 230 & $38(17 \%)$ & & 1 & & 1 \\
\hline Yes & 20 & $8(40 \%)$ & 0.02 & $3.4(1.3-8.8)$ & 0.08 & $2.7(0.9-8.4)$ \\
\hline \multicolumn{7}{|c|}{ History of seizure } \\
\hline No & 238 & $42(18 \%)$ & & 1 & & \\
\hline Yes & 13 & $4(31 \%)$ & 0.27 & $2.1(0.6-7.1)$ & & \\
\hline \multicolumn{7}{|c|}{ Thiotepa regimen } \\
\hline $600 \mathrm{mg} / \mathrm{m}^{2}$ & 129 & $18(14 \%)$ & & & & \\
\hline $720 \mathrm{mg} / \mathrm{m}^{2}$ & 76 & $17(22 \%)$ & $0.18^{e}$ & & & \\
\hline $900 \mathrm{mg} / \mathrm{m}^{2}$ & 46 & $11(24 \%)$ & & & & \\
\hline \multicolumn{7}{|l|}{ Alizapride $^{\mathrm{d}}$} \\
\hline No & 126 & $19(15 \%)$ & & 1 & & 1 \\
\hline Yes & 94 & $25(27 \%)$ & 0.04 & $2.0(1.0-4.0)$ & 0.13 & $1.7(0.8-3.6)$ \\
\hline \multicolumn{7}{|l|}{ Aprepitant $^{d}$} \\
\hline No & 213 & $41(19 \%)$ & & 1 & & \\
\hline Yes & 7 & $3(43 \%)$ & 0.14 & $3.1(0.7-14.6)$ & & \\
\hline \multicolumn{7}{|l|}{ Antipsychotic ${ }^{d}$} \\
\hline No & 180 & $34(19 \%)$ & & 1 & & \\
\hline Yes & 40 & $10(25 \%)$ & 0.39 & $1.4(0.6-3.2)$ & & \\
\hline \multicolumn{7}{|c|}{ Proton Pump Inhibitor ${ }^{d}$} \\
\hline No & 213 & $43(20 \%)$ & & 1 & & \\
\hline Yes & 7 & $1(14 \%)$ & 1 & $0.7(0.1-5.6)$ & & \\
\hline \multicolumn{7}{|c|}{ Histamine H2-receptor antagonist ${ }^{d}$} \\
\hline No & 215 & $42(20 \%)$ & & 1 & & \\
\hline Yes & 5 & $2(40 \%)$ & 0.26 & $2.7(0.4-17)$ & & \\
\hline \multicolumn{7}{|c|}{ Simple analgesics ${ }^{d}$} \\
\hline \multicolumn{7}{|c|}{ i.e. acetaminophen, nefopam } \\
\hline No & 144 & $20(13 \%)$ & & 1 & & \\
\hline Yes & 76 & 14 (18\%) & 0.40 & $1.4(0.7-3.0)$ & & \\
\hline
\end{tabular}


Table 3 Univariate and multivariate logistic regression analysis of factors contributing to NAE (Continued)

\begin{tabular}{|c|c|c|c|c|c|c|}
\hline & $\mathrm{n}$ & NAE (\%) & univariate $P^{a}$ & $\begin{array}{l}\text { univariate } \\
\text { OR ( } 95 \% \mathrm{Cl})\end{array}$ & multivariate $P^{b}$ & $\begin{array}{l}\text { multivariate } \\
\text { OR }(95 \% \text { Cl) }\end{array}$ \\
\hline \multicolumn{7}{|c|}{ Weak opioids $^{d}$} \\
\hline \multicolumn{7}{|c|}{ i.e. tramadol, codeine, dextropropoxyphen } \\
\hline No & 167 & $20(12 \%)$ & & 1 & & 1 \\
\hline Yes & 53 & $24(45 \%)$ & 0.0001 & $6.1(3.0-12.4)$ & 0.0001 & $6.3(3.0-13.4$ \\
\hline \multicolumn{7}{|c|}{ Strong opioids ${ }^{d}$} \\
\hline \multicolumn{7}{|c|}{ i.e. morphine, pethidine } \\
\hline No & 211 & $44(21 \%)$ & & 1 & & \\
\hline Yes & 9 & $4(44 \%)$ & 0.09 & $3.0(0.8-11.8)$ & & \\
\hline
\end{tabular}

${ }^{\mathrm{a}}$ Fisher exact

${ }^{\mathrm{b}}$ Taking into account 4 factors: brain tumour (yes/no); neurological disorder at baseline (yes/no); alizapride intake (yes/no); weak opioids (yes/no)

'Student $t$ test

${ }^{\mathrm{d}}$ Data missing for 31 patients

${ }^{e}$ Chi-square test (2 df)

fMean (SD)

incidence of neurotoxicity related to high-dose thiotepa, which had been administered below the defined limiting dose $\left(1005\right.$ to $\left.1125 \mathrm{mg} / \mathrm{m}^{2}\right)$ in all the courses, in accordance with the consensus guidelines [21]. Neurological complications have previously been reported after thiotepa combined with total body irradiation [25-27] or with another cytotoxic agent such as busulfan [28], busulfan and melphalan [29], carboplatin and cyclophosphamide [30], etoposide [31]. It is noteworthy that most children with HDCT receive many other medicines that can cause various neurological signs: opioids and drowsiness, anti-emetics and extrapyramidal syndrome, benzodiazepine and behavioural disorders [32]. Causality studies had then failed to demonstrate unambiguous involvement of thiotepa in the development of neurological disorders. NAE observed in our study are mostly of central nervous system origin with $9.6 \%$ of symptoms described as severe (grade 3 or 4). All NAE were reversible and devoid of sequelae, and had not contraindicated rechallenge with high-dose thiotepa.

Various pathomechanisms can explain drug-induced neurological disorders. In this study, we showed that a brain tumour could be an independent risk factor, which could increase the risk for thiotepa-related neurotoxicity 2.2-fold. Drugs with the highest neurotoxicity are therefore those that readily cross the blood-brain barrier. Lipid-soluble agents with a low molecular weight, such as thiotepa and tepa enter the brain easily [32]. Damage to the blood-brain barrier could facilitate the passage of drugs into the brain. Diseases such as malignant brain tumours, which damage the blood-brain barrier, would facilitate the direct neurotoxic effect of such drugs [33, 34].

In our study, we found no influence of renal failure on the occurrence of high-dose thiotepa- related NAE. However, these results should be considered with caution.
Only 12 children had renal disruption, classified as an early-stage disorder. Among them, two children had experienced a NAE. Even moderate renal disruption has been described as possibly capable of increasing exposure to thiotepa by $43 \%$ and exposure to tepa by $157 \%$ [35]. Therefore thiotepa dose adjustments regarding renal clearance remain recommended.

In this study, we showed that intake of a weak opioid, especially tramadol, could be an independent risk factor for thiotepa-related NAE. Drug-related iatrogenia is a major source of treatment failures, especially when multiple medications are used. CYP3A4 and CYP2B6 are the main cytochrome enzymes involved in the metabolism of thiotepa to tepa $[12,13]$. Thiotepa was described to be a highly potent, irreversible inhibitor of CYP2B6, which can lead to a risk of a self-induced overdose via a metabolic predisposition of each patient. Caution should be exercised when using thiotepa combined with CYP2B6 substrates, such as tramadol [36, 37]. In addition, aprepitant was described as an CYP3A4 inhibitor which can lead to an overdose of thiotepa $[38,39]$. In this study, comedication with aprepitant was not significantly associated with NAE, possibly because of a lack of statistical power (only 3 to 7 patients had been treated with that drug).

Otherwise, interindividual variability in alkylating agent pharmacokinetics may lead to unpredictable toxicity and efficacy. A poor metabolizer phenotype was described as responsible for an increase in exposure to thiotepa and for an increase in the severity of mucositis [40]. This variability is particularly important in cancer therapy due to the narrow therapeutic window of anticancer agents. Interindividual variability in thiotepa clearance has been described as ranging from 28 to $90 \%$, with variability of exposure to tepa after the administration of high-dose thiotepa ranging from 15 to 50\% [41]. A pharmacogenetic analysis could therefore be considered 
before starting high-dose chemotherapy to better predict the metabolizer phenotype [17].

In our study, we have shown that tramadol used concomitantly with high-dose thiotepa could increase the risk of NAE 6.3-fold. Tramadol is a synthetic opiate that is chemically similar to codeine. Its antinociceptive effects are mediated via a combination of the agonist effects of $\mu$-opioid receptors and inhibition of the reuptake of serotonin and norepinephrine [42]. This second property is an important element of analgesia, but also a major element in the risk of developing NAE. Indeed, tramadol is known to lower the seizure threshold and has been reported to be responsible for seizures at therapeutic and toxic doses [43-45]. Similarly, the risk of serotonin syndrome is possible at the usual doses, and seems more common when overused or combined with potent inhibitors of metabolic pathways [46]. The main metabolite of tramadol, which has a 200-fold higher agonist effect for $\mu$-opioid receptors than tramadol, results from the metabolism of tramadol by CYP2D6. However, another metabolic pathway of tramadol, as described above, passes through CYP2B6 and CYP3A4 [47]. Thus, concomitant use of tramadol and high-dose thiotepa, a CYP2B6 inhibitor, could be responsible for an overdose of tramadol, which could promote the emergence of neurological complications via monoaminergic overactivity.

An alternate hypothesis is that there is an unmeasured confounder that leads to both increased risk of NAE and increased need for pain control, hence the observed association with exposure to the weak opiates.

In clinical research, the gold standard is the prospective randomized controlled trial. Retrospective cohort studies, as performed in our study, are in principle subject to multiple risks of bias [48]. Selection bias of patients was reduced or cancelled by the decision to analyze all children with solid tumours treated with high-dose thiotepa followed by ASCT. This bias could therefore only occur if the active file of patients under treatment in the paediatric oncology unit had already been selected simply through admission to the unit. Concerning NAE, it is likely that all qualifying events have not been recorded across the 25 year period, and in particular for low-grade events that may be missing from the records. Regarding interpretation bias, the reading grid was carried out before and the collection was standardized for all patients. Finally, we sought to prevent confounding bias by conducting an analysis of univariate and multivariable logistic regression.

\section{Conclusions}

This study estimates an incidence of $18.3 \%$ of high-dose thiotepa-related NAE. These neurological complications resolved without sequelae and rechallenge with thiotepa was possible. A brain tumour and tramadol treatment were found to be possible independent risk factors for thiotepa-related neurotoxicity. Identifying markers for individual susceptibilities is mandatory in order to develop customised treatment approaches for cancer patients treated with intensive chemotherapy.

\begin{abstract}
Abbreviations
ASCT: Autologous stem cell transplantation; Cl: Confidence interval; CSF: Cerebrospinal fluid; GFR: Glomerular filtration rate; GST: Glutathione S-transferase; HDCT: High-dose chemotherapy; IQR: Interquartile range; MTD: Maximum tolerated dose; NAE: Neurological adverse events; OR: Odds Ratio
\end{abstract}

\section{Acknowledgements}

We thank Lorna Saint Ange for editing this manuscript.

\section{Funding}

None

Availability of data and materials

The datasets used and/or analysed during the current study are available from the corresponding author on reasonable request.

\section{Authors' contributions}

FL and CD contributed to the study idea. CM, FL, and CD designed the study. CM did the literature search and collected data. AL did statistical analyses. CM, $F L, A L$, and $C D$ interpreted data. CM wrote the report. FL, AL, SD, DVC, and CD contributed to the development of the report by revising it critically. CM, FL, AL, $S D, D V C$, and $C D$ approved the final report.

\section{Ethics approval and consent to participate}

This study was approved by the local ethics committee of Gustave Roussy ( $\left.n^{\circ} 26 / 007\right)$. The parents/guardians gave their written informed consent for the retrospective analysis of clinical data according to the institutional review board of the Gustave Roussy Campus.

Consent for publication

Not applicable.

\section{Competing interests}

The authors declare that they have no competing interests.

\section{Publisher's Note}

Springer Nature remains neutral with regard to jurisdictional claims in published maps and institutional affiliations.

\section{Author details}

${ }^{1}$ Department of Clinical Pharmacy, Gustave-Roussy cancer campus, 114 Rue Edouard Vaillant, 94805 Villejuif, France. ${ }^{2}$ Department of Biostatistics and Epidemiology, Gustave-Roussy, Villejuif, France. ${ }^{3}$ Department of Pediatric and Adolescent Oncology, Gustave-Roussy, Villejuif, France. ${ }^{4}$ Faculty of Pharmacy of Paris, Sorbonne-Paris University, 75006 Paris, France. ${ }^{5}$ EA 7348 MOS, Ecole des Hautes Etudes en Santé Publique, 35000 Rennes, France.

Received: 22 February 2017 Accepted: 5 February 2018

Published online: 13 February 2018

\section{References}

1. Banna GL, Simonelli M, Santoro A. High-dose chemotherapy followed by autologous hematopoietic stem-cell transplantation for the treatment of solid tumors in adults: a critical review. Curr Stem Cell Res Ther. 2007:2:65-82.

2. Ladenstein R, Philip T, Gardner H. Autologous stem cell transplantation for solid tumors in children. Curr Opin Pediatr. 1997:9:55-69.

3. Frei E 3rd, Teicher BA, Holden SA, Cathcart KN, Wang YY. Preclinical studies and clinical correlation of the effect of alkylating dose. Cancer Res. 1988;48:6417-23.

4. Finlay JL, Goldman S, Wong MC, Cairo M, Garvin J, August C, Cohen BH, Stanley P. Zimmerman RA, Bostrom B, Geyer JR, Harris RE, Sanders J, Yates AJ, Boyett JM, Packer RJ. Pilot study of high-dose thiotepa and etoposide with autologous bone 
marrow rescue in children and young adults with recurrent CNS tumors. The Children's cancer group. J Clin Oncol. 1996;14:2495-503.

5. Ridola V, Grill J, Doz F, Gentet JC, Frappaz D, Raquin MA, Habrand JL, Sainte-Rose C, Valteau-Couanet D, Kalifa C. High-dose chemotherapy with autologous stem cell rescue followed by posterior fossa irradiation for local medulloblastoma recurrence or progression after conventional chemotherapy. Cancer. 2007;110: 156-63.

6. Saarinen-Pihkala UM, Hovi L, Koivusalo A, Jahnukainen K, Karikoski R, Sariola H, Wikström S. Thiotepa and melphalan based single, tandem, and triple high dose therapy and autologous stem cell transplantation for high risk neuroblastoma. Pediatr Blood Cancer. 2012;59:1190-7.

7. Saarinen UM, Pihko H, Makipernaa A. High-dose thiotepa with autologous bone marrow rescue in recurrent malignant oligodendroglioma: a case report. J Neuro-Oncol. 1990;9:57-61.

8. Saarinen UM, Hovi L, Makipernaa A, Riikonen P. High-dose thiotepa with autologous bone marrow rescue in pediatric solid tumors. Bone Marrow Transplant. 1991;8:369-76.

9. Tabone MD, Kalifa C, Rodary C, Raquin M, Valteau-Couanet D, Lemerle J. Osteosarcoma recurrences in pediatric patients previously treated with intensive chemotherapy. J Clin Oncol. 1994;12:2614-20.

10. Huitema AD, Mathot RA, Tibben MM, Schellens $J H$, Rodenhuis S, Beijnen JH. Population pharmacokinetics of thioTEPA and its active metabolite TEPA in patients undergoing high-dose chemotherapy. Br J Clin Pharmacol. 2001;51: 61-70.

11. Miller B, Tenenholz T, Egorin MJ, Sosnovsky G, Rao NU, Gutierrez PL. Cellular pharmacology of N,N',N"-triethylene thiophosphoramide. Cancer Lett 1988; 41:157-168.

12. Jacobson PA, Green K, Birnbaum A, Remmel RP. Cytochrome P450 isozymes $3 \mathrm{~A} 4$ and $2 \mathrm{~B} 6$ are involved in the in vitro human metabolism of thiotepa to TEPA. Cancer Chemother Pharmacol. 2002:49:461-7.

13. Dirven HA, Dictus EL, Broeders NL, van Ommen B, van Bladeren PJ. The role of human glutathione S-transferase isoenzymes in the formation of glutathione conjugates of the alkylating cytostatic drug thiotepa. Cancer Res. 1995;55:1701-6.

14. Heideman RL, Packer RJ, Reaman GH, Allen JC, Lange B, Horowitz ME, Steinberg SM, Gillespie A, Kovnar EH, Balis FM. A phase II evaluation of thiotepa in pediatric central nervous system malignancies. Cancer. 1993; 72:271-5.

15. Maanen MJ, Smeets CJ, Beijnen JH. Chemistry, pharmacology and pharmacokinetics of N,N',N" -triethylenethiophosphoramide (ThioTEPA). Cancer Treat Rev 2000;26:257-268.

16. Cohen BE, Egorin MJ, Kohlhepp EA, Aisner J, Gutierrez PL. Human plasma pharmacokinetics and urinary excretion of thiotepa and its metabolites. Cancer Treat Rep. 1986;70:859-64

17. Ekhart C, Doodeman VD, Rodenhuis S, Smits PH, Beijnen JH, Huitema AD. Polymorphisms of drug-metabolizing enzymes (GST, CYP2B6 and CYP3A) affect the pharmacokinetics of thiotepa and tepa. Br J Clin Pharmacol. 2009; 67:50-60.

18. Herzig R, Brown R, Fay J. Phase I and II studies of high dose $N, N^{\prime}, N^{\prime \prime}$-triethylene thiophosphoramide and autologous marrow transplantation in patients with refractory malignancies. Cancer Res Ther Control 1990;1:141-153.

19. Lucidarme N, Valteau-Couanet D, Oberlin O, Couanet D, Kalifa C, Beaujean F, Lapierre V, Hartmann O. Phase II study of high-dose thiotepa and hematopoietic stem cell transplantation in children with solid tumors. Bone Marrow Transplant. 1998:22:535-40.

20. Przepiorka D, Madden T, Ippoliti C, Estrov Z, Dimopoulos M. Dosing of thioTEPA for myeloablative therapy. Cancer Chemother Pharmacol. 1995;37:155-60.

21. Wolff SN, Herzig RH, Fay JW, LeMaistre CF, Brown RA, Frei-Lahr D, Stranjord S, Giannone L, Coccia P, Weick JL. High-dose N,N',N"-triethylenethiophosphoramide (thiotepa) with autologous bone marrow transplantation: phase I studies. Semin Oncol 1990;17:2-6.

22. Lazarus HM, Reed MD, Spitzer TR, Rabaa MS, Blumer JL. High-dose i.v. thiotepa and cryopreserved autologous bone marrow transplantation for therapy of refractory cancer. Cancer Treat Rep. 1987;71:689-95.

23. Schwartz GJ, Haycock GB, Edelmann CM Jr, Spitzer A. A Simple estimate of glomerular filtration rate in children derived from body length and plasma creatinine. Pediatrics. 1976:58:259-63.

24. Begaud B. Criteria of imputability in accidents of drug-induced origin. Rev Prat. 2000;50:1803-6.

25. Freilich RJ, Delattre JY, Monjour A, DeAngelis LM. Chemotherapy without radiation therapy as initial treatment for primary CNS lymphoma in older patients. Neurology. 1996;46:435-9.
26. Weiss HD, Walker MD, Wiernik PH. Neurotoxicity of commonly used antineoplastic agents (first of two parts). N Engl J Med. 1974;291:75-81.

27. Kaplan RS, Wiernik PH. Neurotoxicity of antineoplastic drugs. Semin Oncol. 1982;9:103-30

28. Kalifa C, Hartmann O, Demeocq F, Vassal G, Couanet D, Terrier-Lacombe MJ, Valteau D, Brugieres L, Lemerle J. High-dose Busulfan and thiotepa with autologous bone marrow transplantation in childhood malignant brain tumors: a phase II study. Bone Marrow Transplant. 1992;9:227-33.

29. Hara J, Osugi Y, Ohta H, Matsuda Y, Nakanishi K, Takai K, Fujisaki H, Tokimasa S, Fukuzawa M, Okada A, Okada S. Double-conditioning regimens consisting of thiotepa, melphalan and busulfan with stem cell rescue for the treatment of pediatric solid tumors. Bone Marrow Transplant. 1998;22:7-12.

30. Antman K, Eder JP, Elias A, Ayash L, Shea TC, Weissman L, Critchlow J, Schryber SM, Begg C, Teicher BA. High-dose thiotepa alone and in combination regimens with bone marrow support. Semin Oncol. 1990;17:33-8.

31. Kramer ED, Packer RJ, Ginsberg J, Goldman S, Thompson S, Bayer LA, Shen V, Harris R, Khan S, Finlay JL. Acute neurologic dysfunction associated with high-dose chemotherapy and autologous bone marrow rescue for primary malignant brain tumors. Pediatr Neurosurg. 1997;27:23-237.

32. Orbach D, Brisse H, Doz F. Central neurological manifestations during chemotherapy in children. Arch Pediatr. 2003;10:533-9.

33. Provenzale JM, Mukundan S, Dewhirst M. The role of blood-brain barrier permeability in brain tumor imaging and therapeutics. AJR Am J Roentgenol. 2005;185:763-7.

34. Deeken JF, Loscher W. The blood-brain barrier and cancer: transporters, treatment, and Trojan horses. Clin Cancer Res. 2007:13:1663-74.

35. Ekhart C, Kerst JM, Rodenhuis S, Beijnen JH, Huitema AD. Altered cyclophosphamide and thiotepa pharmacokinetics in a patient with moderate renal insufficiency. Cancer Chemother Pharmacol. 2009;63: 375-9.

36. Richter T, Schwab M, Eichelbaum M, Zanger UM. Inhibition of human CYP2B6 by $N_{1} N^{\prime}, N^{\prime \prime}$-triethylenethiophosphoramide is irreversible and mechanism-based. Biochem Pharmacol 2005:69:517-524.

37. Nelson EM, Philbrick AM. Avoiding serotonin syndrome: the nature of the interaction between tramadol and selective serotonin reuptake inhibitors. Ann Pharmacother. 2012;46:1712-6.

38. de Jonge ME, Huitema AD, Holtkamp MJ, van Dam SM, Beijnen JH, Rodenhuis S. Aprepitant inhibits cyclophosphamide bioactivation and thiotepa metabolism. Cancer Chemother Pharmacol. 2005;56:370-8.

39. Howell JE, Szabatura AH, Hatfield Seung A, Nesbit SA. Characterization of the occurrence of ifosfamide-induced neurotoxicity with concomitant aprepitant. J Oncol Pharm Pract. 2008;14:157-62.

40. Huitema AD, Spaander M, Mathjt RA, Tibben MM, Holtkamp MJ, Beijnen JH, Rodenhuis $\mathrm{S}$. Relationship between exposure and toxicity in high-dose chemotherapy with cyclophosphamide, thiotepa and carboplatin. Ann Oncol. 2002:13:374-84.

41. Huitema AD, Smits KD, Mathot RA, Schellens JH, Rodenhuis S, Beijnen JH. The clinical pharmacology of alkylating agents in high-dose chemotherapy. Anti-Cancer Drugs. 2000;11:515-33.

42. Duke AN, Bigelow GE, Lanier RK, Strain EC. Discriminative stimulus effects of tramadol in humans. J Pharmacol Exp Ther. 2011;338:255-62.

43. Jovanovic-Cupic V, Martinovic Z, Nesic N. Seizures associated with intoxication and abuse of tramadol. Clin Toxicol (Phila). 2006:44:143-6.

44. Ripple MG, Pestaner JP, Levine BS, Smialek JE. Lethal combination of tramadol and multiple drugs affecting serotonin. Am J Forensic Med Pathol. 2000;21(4):370

45. Daubin C, Quentin C, Goulle JP, Guillotin D, Lehoux P, Lepage O, Charbonneau P. Refractory shock and asystole related to tramadol overdose. Clin Toxicol (Phila). 2007:45:961-4.

46. Sansone RA, Sansone LA. Tramadol: seizures, serotonin syndrome, and coadministered antidepressants. Psychiatry (Edgmont). 2009:6:17-21.

47. Grond S, Sablotzki A. Clinical pharmacology of tramadol. Clin Pharmacokinet. 2004:43:879-923.

48. Tripepi G, Jager KJ, Dekker FW, Zoccali C. Selection bias and information bias in clinical research. Nephron Clin Pract. 2010;115:94-9. 